\title{
Benzoxazinoids: Reactivity and Modes of Action of a Versatile Class of Plant Chemical Defenses
}

\author{
Felipe C. Wouters, Jonathan Gershenzon and Daniel G. Vassão* \\ Department of Biochemistry, Max Planck Institute for Chemical Ecology, Hans-Knöll-Str. 8, \\ 07745 Jena, Germany
}

\begin{abstract}
In order to protect themselves from biotic stresses, including enemies and competitors, many plants recruit defensive secondary metabolites. Compounds containing a 2-hydroxy-2H-1,4benzoxazin-3(4H)-one skeleton and their derivatives, collectively known as benzoxazinoids, are common secondary metabolites in many grasses, including important cereal crops such as maize, wheat, and rye, as well as several dicot species. This diverse class of compounds is known for its broad range of antifeedant, insecticidal, antimicrobial, and allelopathic activities. However, the mechanisms underlying such biological activities are not yet completely understood. The present review aims to summarize the current knowledge on the chemical reactivity of benzoxazinoids in biological systems and associate it to their proposed modes of action. Structure-activity relationships for a wide spectrum of biological effects are critically discussed and directions for future research are addressed.
\end{abstract}

Keywords: benzoxazinoids, plant defenses, chemical ecology, natural products, mode of action

\section{Introduction}

Compounds with the 2-hydroxy-2H-1,4-benzoxazin$3(4 H)$-one skeleton (benzoxazinones) and their degradation products (benzoxazolinones) have been recognized as general defense metabolites from plants, being involved in antifeedant, insecticidal, antimicrobial, and allelopathic activities. ${ }^{1}$ Given the variety of biologically relevant structures in this group, we will refer to benzoxazinones (both acetal glucosides and hemiacetal aglucone forms) and benzoxazolinones collectively as benzoxazinoids (BXDs) in this article. These compounds are given acronyms based on their official names, such that 2,4-dihydroxy7-methoxy-2H-1,4-benzoxazin-3(4H)-one is normally referred to as DIMBOA, and its glucoside, $(2 R)-2-\beta$ D-glucopyranosyloxy-4-hydroxy-7-methoxy- $2 H-1,4-$ benzoxazin-3(4H)-one, as DIMBOA-Glc. The most common naturally occurring BXD structures and their relationships are shown in Scheme 1.

This group of nitrogen-containing secondary metabolites is present in many grasses (Poaceae), including economically important crops such as maize, wheat, and rye (but not rice, oat, sorghum, and cultivated barley). ${ }^{1}$ BXDs are also found in a few species within the dicot

*e-mail: vassao@ice.mpg.de families Acanthaceae, Ranunculaceae, Plantaginaceae, and Lamiaceae. ${ }^{2,3}$

The BXD biosynthetic pathway has been mostly established in maize ${ }^{2,4}$ and is summarized in Scheme 2. The biosynthesis of BXDs, their evolution in plants, and related genetic aspects have been recently comprehensively reviewed. ${ }^{2,3,5}$ The enzyme BX1 (named for the benzoxazineless phenotype of its homozygous mutant, bx1) catalyzes the first committed step of the pathway, converting indole-3-glycerol phosphate into indole in the chloroplasts. This enzyme is a homolog of the subunit $\alpha$ of tryptophan synthase, which performs the same reaction but is coupled to a $\beta$ subunit that further converts indole to tryptophan without releasing it from the enzyme complex. Free indole produced by BX1 is then oxidized by four cytochrome P450-dependent monooxygenases, BX2-BX5, which are located in the endoplasmic reticulum and are substrate-specific and regioselective for the introduction of oxygen atoms. The resulting DIBOA is the first toxic intermediate in the pathway and is glucosylated by UDP-glucosyltransferases BX8 and BX9, presumably to minimize autotoxicity and provide a stable intermediate for further modifications in the cytoplasm. DIBOA-Glc can be hydroxylated by the 2-oxoglutaratedependent dioxygenase BX6, and $O$-methylated by $O$-methyltransferase BX7, yielding DIMBOA-Glc. 


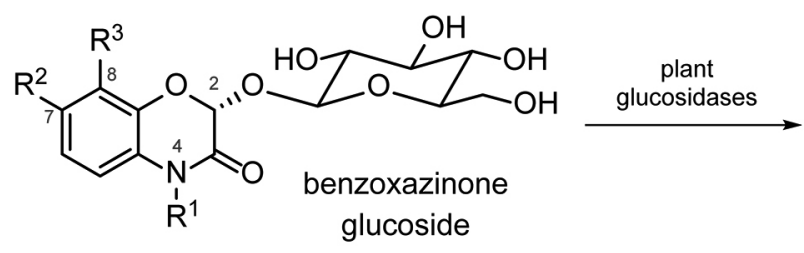

\begin{tabular}{cccc}
\hline Benzoxazinone & $\mathbf{R}^{1}$ & $\mathbf{R}^{2}$ & $\mathbf{R}^{3}$ \\
\hline HBOA & $\mathrm{H}$ & $\mathrm{H}$ & $\mathrm{H}$ \\
DHBOA & $\mathrm{H}$ & $\mathrm{OH}$ & $\mathrm{H}$ \\
$\mathrm{HMBOA}$ & $\mathrm{H}$ & $\mathrm{OMe}$ & $\mathrm{H}$ \\
$\mathrm{HM}_{2} \mathrm{BOA}$ & $\mathrm{H}$ & $\mathrm{OMe}$ & $\mathrm{OMe}$ \\
DIBOA & $\mathrm{OH}$ & $\mathrm{H}$ & $\mathrm{H}$ \\
TRIBOA & $\mathrm{OH}$ & $\mathrm{OH}$ & $\mathrm{H}$ \\
DIMBOA & $\mathrm{OH}$ & $\mathrm{OMe}$ & $\mathrm{H}$ \\
$\mathrm{DIM}_{2} \mathrm{BOA}$ & $\mathrm{OH}$ & $\mathrm{OMe}$ & $\mathrm{OMe}$ \\
$\mathrm{HDMBOA}$ & $\mathrm{OMe}$ & $\mathrm{OMe}$ & $\mathrm{H}$ \\
$\mathrm{HDM}_{2} \mathrm{BOA}$ & $\mathrm{OMe}$ & $\mathrm{OMe}$ & $\mathrm{OMe}$ \\
\hline
\end{tabular}

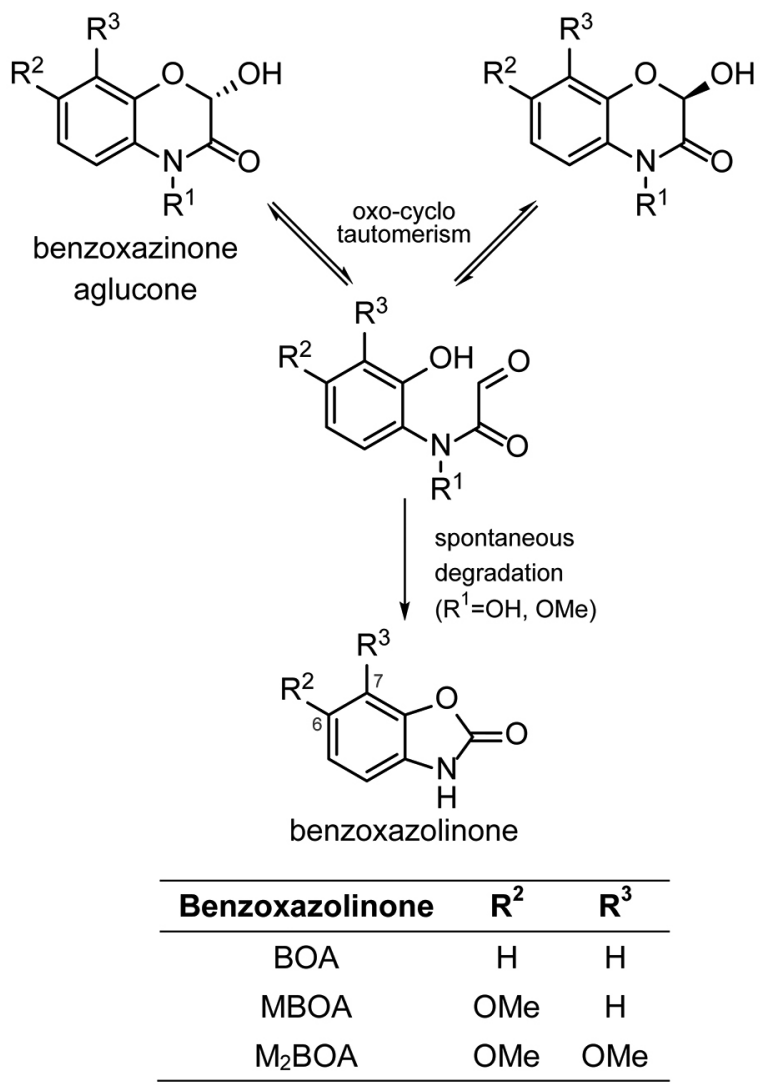

Scheme 1. Hydrolysis of naturally occurring benzoxazinone glucosides and degradation to benzoxazolinones via oxo-cyclo ring-chain tautomerism.

Recently, another three homologous $O$-methyltransferases, $\mathrm{BX} 10, \mathrm{BX} 11$, and BX12, were implicated in the reaction from DIMBOA-Glc to HDMBOA-Glc. ${ }^{4}$ The stable glucosides are considered to be transported to and stored in the vacuole. ${ }^{6}$ Since $\beta$-glucosidases that use BXD glucosides as substrates are present in chloroplasts, cell walls, and cytoplasm, no hydrolysis normally occurs in intact tissue. ${ }^{7}$

Upon disruption of the cell structure (by herbivore feeding or pathogen attack), BXD glucosides come into contact with $\beta$-glucosidases and are hydrolyzed to reactive aglucones, which are implicated in the toxicity of BXDs. A similar pattern is also observed for other plant defenses, such as glucosinolates and cyanogenic and iridoid glycosides, that are also activated only upon damage. ${ }^{8,9}$ In roots, BXDs are actively exuded from plant tissue to the soil and thus can exert direct effects on root herbivores, soil microorganisms, and other plants. ${ }^{10,11}$ Benzoxazinone aglucones can spontaneously degrade to benzoxazolinones at rates that depend on their chemical nature and environmental conditions, as will be discussed in more detail below.

The abundance of BXDs and their proportion vary between plant species and varieties and within plants among tissues, developmental stages, and after induction by biotic factors. The total concentrations of BXDs can reach $>0.1 \%$ of fresh weight as in maize leaves after caterpillar attack. ${ }^{12,13}$ The main BXD in rye is DIBOA-Glc, ${ }^{14}$ whereas DIMBOA-Glc is the major BXD in aerial parts of wheat and maize, ${ }^{14,15}$ and HDMBOA-Glc is dominant in maize roots. ${ }^{16}$ In maize, BXDs reach the highest total concentrations in seedlings in less than 10 days after germination, and then decline as the plant grows, ${ }^{15}$ being differently allocated to leaves according to their age ${ }^{17}$ Different compounds show different profiles. For example, HDMBOA-Glc is especially induced after herbivory, ${ }^{12,13}$ fungal attack ${ }^{18}$ and upon jasmonic acid treatment ${ }^{14,19}$ in maize.

Despite the relatively well documented effects of BXDs on insects, microorganisms and plants, little is known about their mode of action in biological systems. As will be discussed throughout this paper, BXDs show a range of chemical reactivities that could be responsible for their biological effects. Moreover, the mechanisms by which they exert toxicity or repellence are not necessarily the same, but may vary depending on factors such as $\mathrm{pH}$ and the physiology of the target organism.

Given the important role of BXDs in interactions with insects, microorganisms, and other plants, understanding 


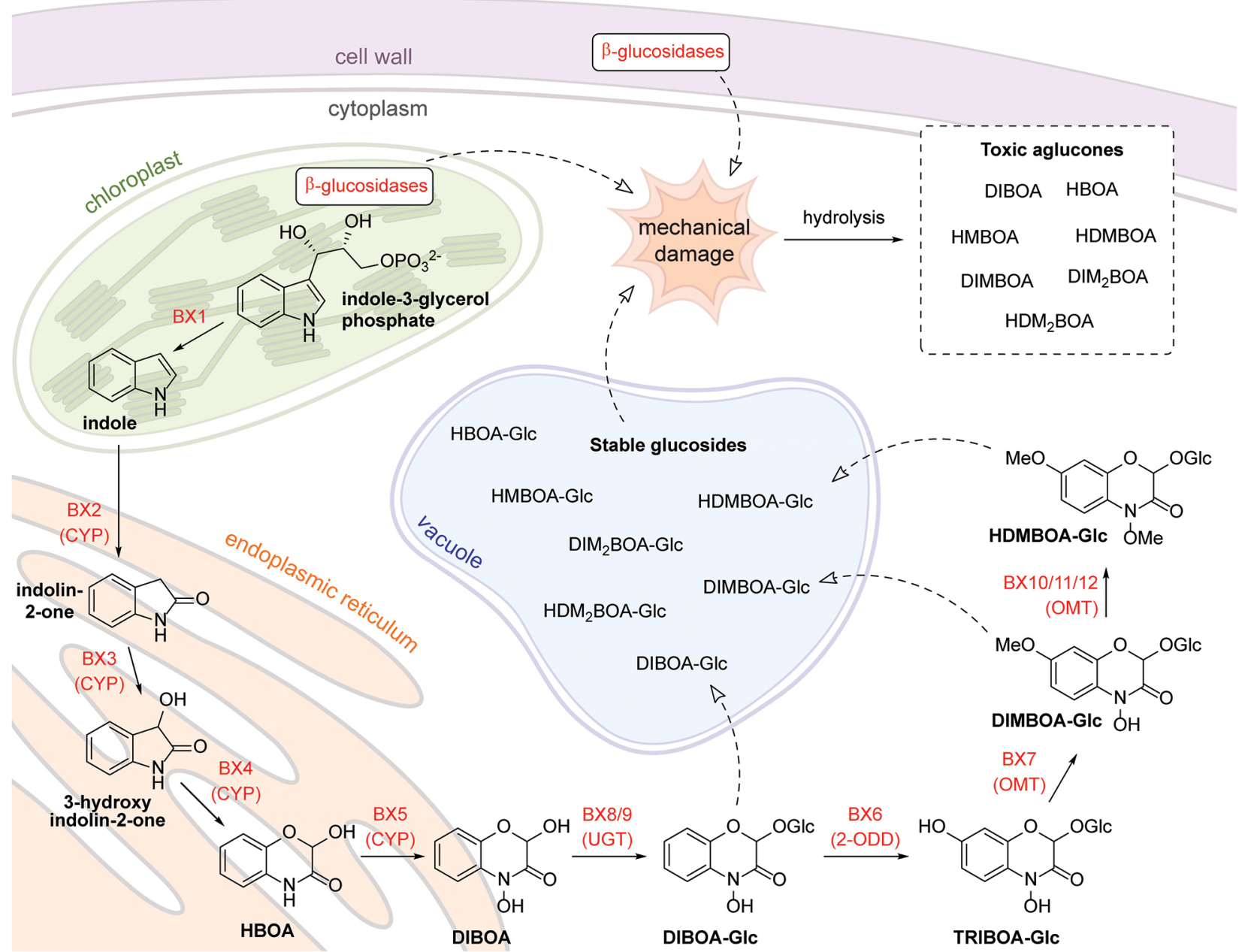

Scheme 2. BXD biosynthesis and model of compartmentalization in a plant cell.

more about this class of compounds is valuable from the viewpoint of pest control, plant breeding, ecology, and evolution of chemical defenses. Several authors have reviewed different aspects of BXDs, including their biological activities, ${ }^{1,20}$ synthetic strategies, ${ }^{21,22}$ chemical reactivities, ${ }^{23}$ and biosynthetic evolution and genetics. ${ }^{2,3}$ These topics are briefly addressed, but not discussed in detail here. The present review aims to summarize and update the current knowledge about BXD chemical properties with emphasis on those that may explain their wide range of biologically relevant activities. Studies on structure-activity relationships are discussed and mechanisms for biological activities are suggested, taking into account the specific features of each of the target organisms.

\section{Chemical Properties of BXDs}

The benzoxazinones shown in Scheme 1 can be divided according to the nature of group $R^{1}$ as lactams $\left(R^{1}=H\right)$, hydroxamic acids $\left(\mathrm{R}^{1}=\mathrm{OH}\right)$, or $N$ - $O$-methylated derivatives
$\left(\mathrm{R}^{1}=\mathrm{OMe}\right)$. These functional groups, together with the substituents $\mathrm{R}^{2}$ and $\mathrm{R}^{3}$ in the aromatic system, greatly influence the stability and reactivity of each compound and therefore their biological activities. The presence of a nitrogen heteroatom in the core structure of benzoxazinones is also considered to lower the stability of these molecules, which is essential to their reactivity. ${ }^{24}$

The acetal group, a feature common to all naturally occurring benzoxazinone glucosides, is remarkably stable $^{25}$ and requires the action of glucosidases for its hydrolysis. The resulting aglucones are cyclic hemiacetals, or lactols, that undergo oxo-cyclo ring-chain tautomerism involving a fast, reversible ring opening reaction. ${ }^{26}$ Proton NMR of HMBOA aglucone confirms that the closed form is predominant, as shown by a singlet at $5.60 \mathrm{ppm}$ corresponding to the lactol proton, as well as the ratios between signals from the open and closed form in the aromatic region. No aldehyde proton is visible, probably because of the low intensity of the signal and hydrationdehydration equilibrium. ${ }^{27}$ As discussed in detail below, the 
open form of benzoxazinone aglucones presents different reactivities than the closed tautomer and is involved in their degradation to benzoxazolinones.

As another consequence of oxo-cyclo ring-chain tautomerism, the aglucones exist as racemic mixtures in solution. Capillary electrophoresis and liquid chromatography do not separate DIBOA and DIMBOA enantiomers, since their interconversion occurs rapidly and continuously during the timescale of these analytical procedures. ${ }^{28,29}$ However, discrimination of DIBOA and DIMBOA enantiomers was achieved by NMR using chiral solvating agents, which form diastereoisomeric solvation complexes. ${ }^{30}$ On the other hand, racemic mixtures of synthetic BXD methyl acetals have been successfully resolved by all three methods, confirming their stability towards hydrolysis and racemization by ring opening. It is interesting to note that all known benzoxazinone glucosides produced by plants are $(2 R)-2-\beta-D$-glucosides ${ }^{31-34}$ that upon glucosidase activity yield racemic mixtures of $(2 R)$ and $(2 S)$ aglucones.

The high activity of BXD $\beta$-glucosidases and the instability of aglucones make the extraction and quantitative analysis of BXDs in natural samples quite challenging. Once plant material is mechanically disrupted for the extraction process, plant $\beta$-glucosidases quickly hydrolyze benzoxazinone glucosides to aglucones. Furthermore, these aglucones spontaneously degrade to benzoxazolinones at different rates depending on the original compound. In general, different extraction methods yield different products..$^{35,36}$ Extraction with water followed by incubation at room temperature and heating allows the hydrolysis of BXD glucosides and further degradation to benzoxazolinones, which are recovered by this method. Maceration of plant material in water followed by acidification to $\mathrm{pH} 3$ yields mostly benzoxazinone aglucones, which are more stable in such conditions. Extraction with boiling methanol ${ }^{35}$ or grinding under liquid nitrogen followed by extraction with methanol and acidified water ${ }^{12}$ avoids the enzymatic hydrolysis of glucosides, which are then the main compounds extracted by these methods.

Detection and quantitation of BXDs have been achieved by different techniques. Colorimetric methods based on the complexation of hydroxamic acids with $\mathrm{Fe}^{\mathrm{III}}$ have been developed, but are limited to this class of compounds and do not distinguish between different hydroxamic acids in extracts. Gas chromatography-mass spectrometry (GCMS) has also been used to analyze BXDs, but requires a derivatization step in order to increase the volatility and stability of the analytes. More recent studies rely on high performance liquid chromatography (HPLC) methods using C18 columns and detection by UV, MS, or MS 2 . Fragmentation patterns of BXD derivatives studied using electrospray time-of-flight mass spectrometry (ESI-TOF MS) have revealed differences in the stability of BXDs in the mass spectrometer ${ }^{37}$ Higher sensitivity is achieved with triple quadrupole instruments operating in multiple reaction monitoring (MRM) mode, but transitions should be carefully chosen, as many BXDs have highly similar fragmentation patterns and share identical transitions and fragments. Extraction and analytical methods for BXDs have been thoroughly evaluated and compared. ${ }^{36}$

Large scale isolation from natural sources has been reported for abundant BXDs in plants. For example, DIMBOA can be extracted from maize seedlings, ${ }^{38}$ while DIBOA-Glc and DIBOA can be obtained from rye. ${ }^{22}$ Maize seedlings grown in dark conditions accumulate more DIMBOA(-Glc) than when illuminated, and therefore this method can be used to improve yields. ${ }^{39}$ Semi-preparative LC on maize extracts can yield pure DIMBOA-Glc, DIMBOA, HMBOA-Glc, HMBOA, and HDMBOA-Glc. ${ }^{12}$ BXDs have also been obtained synthetically, both as their natural structures and analogs with various substitution patterns and functional groups..$^{27,40,41}$ Chemical glucosylation of BXDs, which is particularly challenging due to the control of two stereogenic centers, has also been achieved in a stereoselective fashion. ${ }^{42,43}$ Synthetic approaches to BXDs have been summarized elsewhere ${ }^{21,22}$ and a detailed discussion is out of the scope of this review. Such methodologies enable the access to standards, materials for bioassays, analogs for structure-activity studies, as well as labeled compounds for tracing experiments and mechanism elucidation.

\subsection{Degradation to benzoxazolinones}

Due to harsh extraction methods, the first BXDs isolated were the benzoxazolinones BOA from rye and MBOA from maize and wheat, followed by the discovery that these compounds originate from DIBOA and DIMBOA, respectively. ${ }^{44,45}$ Since then, the degradation of benzoxazinones to benzoxazolinones has been studied and deemed relevant to biological activities of BXDs. Several pathways for this degradation have been suggested, and are summarized in Scheme 3.

In general, lactams (N-H compounds) are not degraded to benzoxazolinones, whereas hydroxamic acids $(\mathrm{N}-\mathrm{OH})$ degrade readily and $\mathrm{N}$-O -methyl derivatives degrade even faster. The half-lives of HDMBOA and DIMBOA aglucones are 1.8 and $25 \mathrm{~h}$, respectively, in buffered $\mathrm{D}_{2} \mathrm{O}$ at $\mathrm{pH} 5.5$ and $24{ }^{\circ} \mathrm{C} .{ }^{46}$ This is caused by the different leaving group character of the $\mathrm{N}$-substituent groups in 


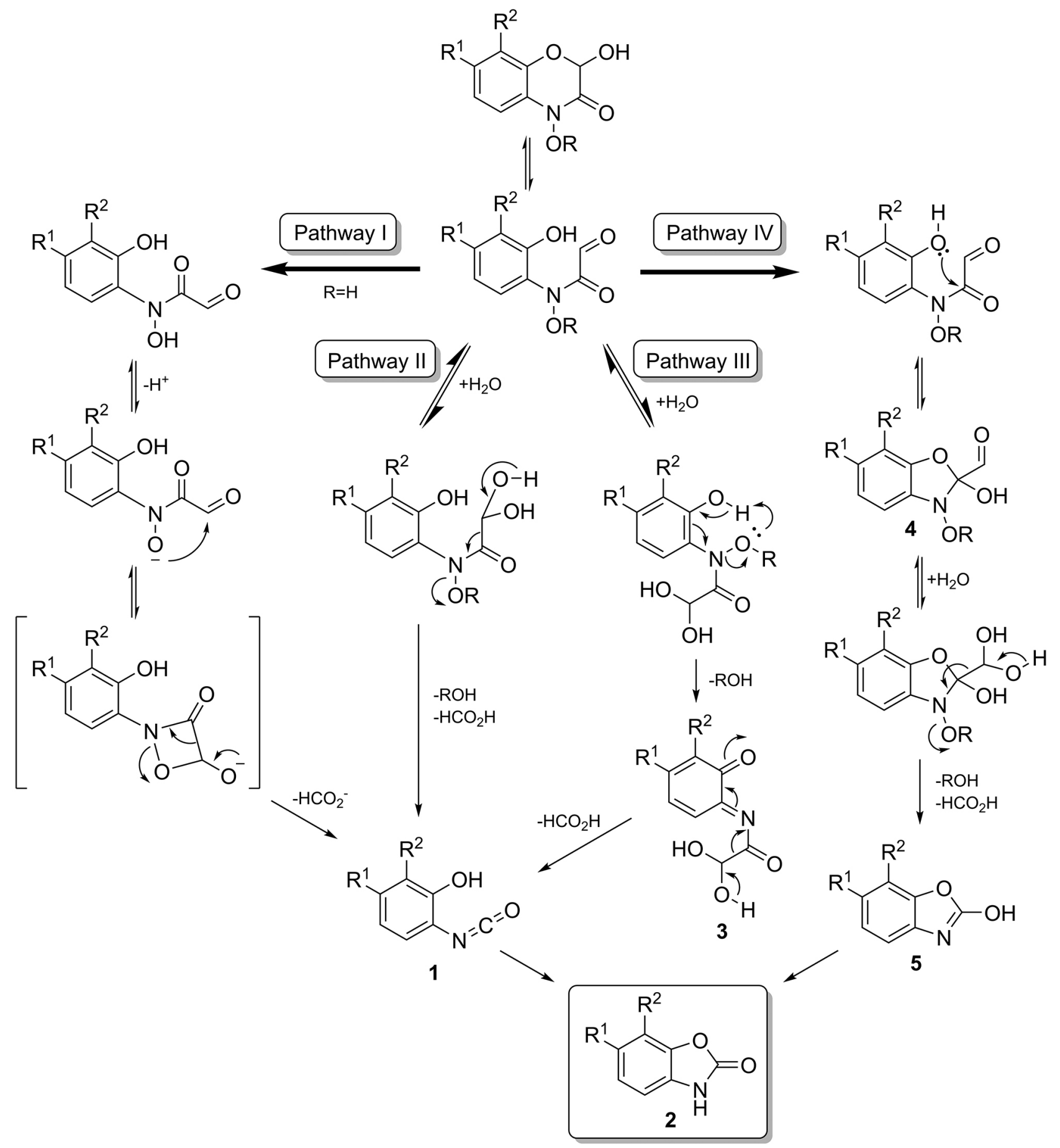

Scheme 3. Proposed mechanisms for the degradation of hydroxamic acids $(\mathrm{R}=\mathrm{H})$ and $N$ - $O$-methyl derivatives $(\mathrm{R}=\mathrm{Me})$ to benzoxazolinones $(\mathbf{2})$.

these molecules, even though other structural features may influence degradation rates. Under $\mathrm{pH} 8.5$ and $48{ }^{\circ} \mathrm{C}$, DIMBOA degrades faster than DIBOA, which is attributed to the strong electron donating effect from the methoxy group at position $7 .{ }^{27}$ As will be discussed in more detail below, an electron rich aromatic ring stabilizes the positive charge on nitrogen during the transition states and accelerates degradation to benzoxazolinones. On the other hand, $\mathrm{DIM}_{2} \mathrm{BOA}$, with methoxy groups on positions 7 and 8, degrades more slowly than DIMBOA. ${ }^{27}$

Pathway I (Scheme 3) was proposed by Bredenberg et al. ${ }^{47}$ after observing by ${ }^{14} \mathrm{C}$ labeling that the carbon atom in position 2 is eliminated as formic acid during benzoxazinone degradation. ${ }^{48}$ The authors suggested a mechanism in which the concentration of hydroxamic acid monoanion, dictated by the $\mathrm{pH}$ of the medium, is critical 
to the reaction rate. This species would act as an internal nucleophile by attacking the aldehyde carbon, forming the isocyanate 1, presumably via a four membered ring, and ultimately leading to the benzoxazolinones $\mathbf{2}$. This pathway is supported by the fact that DIMBOA degradation is faster in organic solvents with high donor numbers (and thus better Lewis bases), which form stronger hydrogen bonds and render the hydroxy group more nucleophilic. ${ }^{49,50}$

Pathway II was suggested by Grambow et al. ${ }^{51}$ as a way to complement the previous pathway and explain why $\mathrm{N}$-O -methylated derivatives also degrade to benzoxazolinones. HDMBOA would not react via pathway I because of the poorly nucleophilic methoxy group bound to the nitrogen atom. Thus, another mechanism was suggested in which the aldehyde function in the open form would be hydrated and undergo a Grob-like heterolytic cleavage, releasing formic acid and the $N$-substituent group, and generating the isocyanate $\mathbf{1}$. This mechanism explains why HDMBOA ( $N$ - $O$-methylated derivative) degrades much faster than DIMBOA (hydroxamic acid), while HMBOA (lactam) does not degrade at all in such conditions. Degradation rates by this mechanism strongly depend on the leaving group character of the $N$-substituent group: $\mathrm{OMe}>\mathrm{OH}>>\mathrm{H}$.

Pathway III was introduced by Maresh et al. ${ }^{46}$ during experiments on HDMBOA degradation. In this route, the open form phenol assists the elimination of the $N$-substituent group, forming an $o$-imidoquinone intermediate $\mathbf{3}$, which was characterized by the authors. This intermediate can then undergo a fragmentation equal to that observed in pathway II, yielding the isocyanate $\mathbf{1}$ and the benzoxazolinone $\mathbf{2}$. In fact, the kinetic data for HDMBOA degradation, as followed by NMR, do not fit pathway III as a unique and linear mechanism. The authors considered both pathways II and III to be competing during degradation of HDMBOA, and included side reactions of the open form hydrate and $o$-imidoquinone into their kinetic model.

Pathway IV, proposed by Smissman et al., ${ }^{52}$ was the first to consider an active role of the phenol function in the degradation reaction. The authors suggested this possibility as an alternative to pathway I since open chain analogs of DIMBOA with the phenol either absent or ether-protected were not observed to degrade to benzoxazolinones. Therefore, the hydroxamic acid and phenol moieties may be required for degradation to occur. In this pathway, the phenol in the open form acts as a nucleophile by attacking the amide carbonyl, producing a 5-membered closed form 4 that is in equilibrium with the other forms. Similarly to pathways II and III, after aldehyde hydration a fragmentation takes place eliminating formic acid and the $N$-substituted group. In this mechanism, however, no isocyanate is formed, but rather the less stable tautomer $\mathbf{5}$ of the benzoxazolinone, which rapidly rearranges yielding the final benzoxazolinone 2 .

The proposed mechanisms all rely on the basicity and nucleophilicity of the phenol and $N$-substituent groups, and the leaving group character of the latter. Since such parameters can vary according to substitution patterns, stereoelectronic and solvent effects, and $\mathrm{pH}$, any of these pathways can in theory be favored depending on the benzoxazinone structure and medium conditions. The decomposition rates of DIMBOA over different $\mathrm{pH}$ values show an asymmetric bell-shaped curve with a maximum around $\mathrm{pH}$ 9.0, which is consistent with DIMBOA acting as a diprotic acid in water $\left(\mathrm{pK}_{\mathrm{a}} 1=6.9, \mathrm{pK}_{\mathrm{a}} 2=10.9\right)$ and each species (DIMBOA and its two conjugated bases) following a different degradation route. ${ }^{49}$ Furthermore, MBOA yield from DIMBOA is not quantitative, ${ }^{53}$ suggesting that other reactions and products might be involved in benzoxazinone degradation, with other potentially reactive and biologically relevant intermediates. Further mechanistic studies relying on modern analytical techniques and comparisons between synthetic BXD analogs could help understand the complexity of benzoxazinone degradation reactions and lead to the discovery of novel pathways, other intermediates and end-products with biological activities.

\section{Possible Modes of Action}

Due to their unique structural features, BXDs may undergo a wide range of reactions with biological relevance. Although the specific modes of action are not yet clear, many studies point to important characteristics of these compounds that might be associated with their described biological activities: (i) electrophilicity of the open form; (ii) electrophilicity of nitrenium ions; (iii) ability of hydroxamic acids to complex metal cations; and (iv) reactivity of benzoxazolinones and derivatives. These features are summarized in Scheme 4 and are discussed below.

\subsection{Electrophilicity of the open form}

The benzoxazinone open form originating from oxocyclo ring-chain tautomerism is an $\alpha$-oxo-aldehyde, which is expected to be a potent electrophile. Therefore, it has been suggested that this group reacts with nucleophilic residues in proteins such as thiols and amines, causing enzymatic inhibition.

DIMBOA has been shown to react with butylamine, from which the imino products observed in Scheme 5 were identified and the reaction kinetics characterized. ${ }^{54}$ No reaction was observed for the 2-O-methyl acetal derivative 


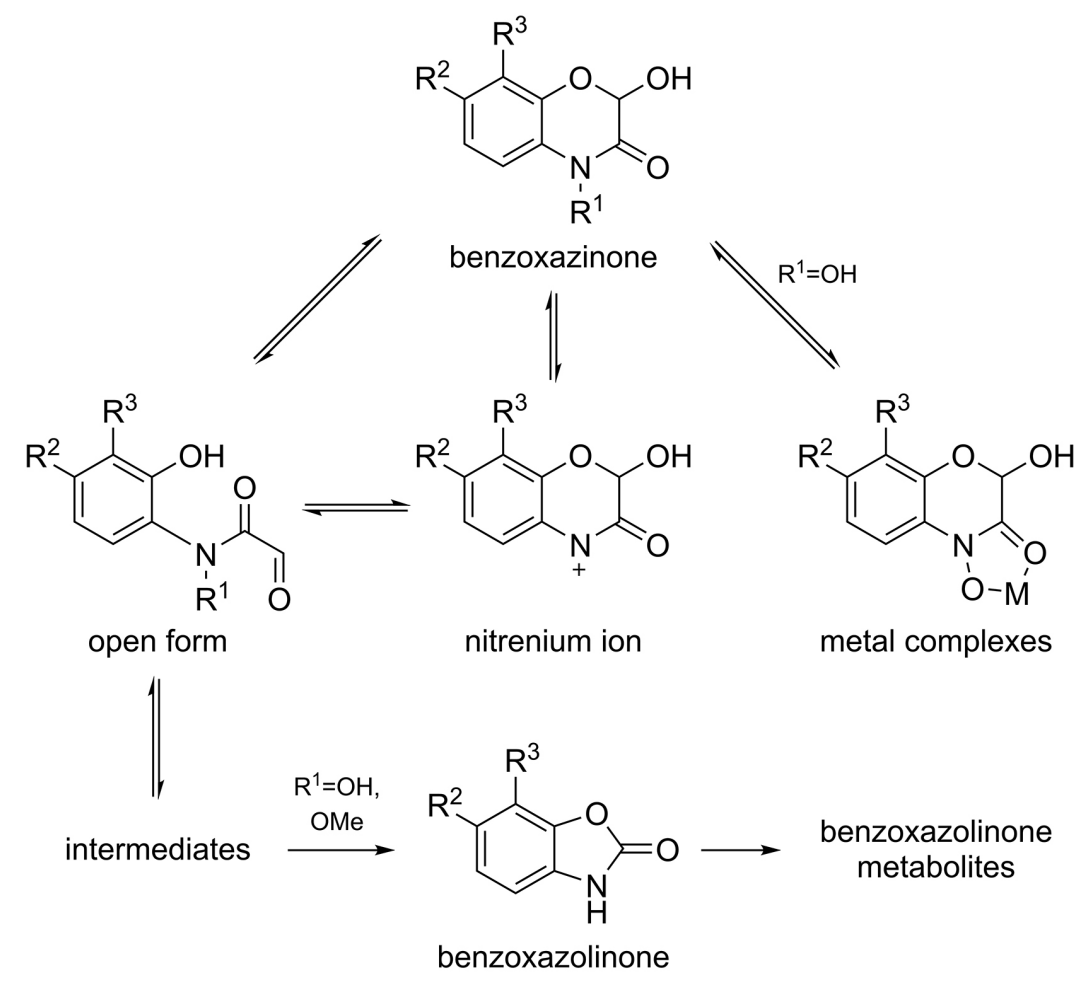

Scheme 4. Summary of possible benzoxazinoid modes of action.

of DIMBOA, suggesting that ring opening is required for the formation of imino adducts. Reaction with HMBOA, a lactam, was slower than for DIMBOA, possibly due to the electron-withdrawing effect from the hydroxamic acid hydroxy group. An analogous reaction was observed with $N$ - $\alpha$-acetyl-lysine, a model compound for the $\varepsilon$-amino groups of lysine residues in enzymes.
Thiols such as ethanethiol, cysteine, mercaptoethanol, and dithiothreitol can also react with DIMBOA, forming the lactam HMBOA, and hemithioacetals originating from the open forms of DIMBOA and HMBOA, shown in Scheme 5. ${ }^{55}$ The species to react were found to be the undissociated hydroxamic acid and the thiolate anion; thus reaction rates were correlated to thiol $\mathrm{pK}_{\mathrm{a}}$<smiles>COc1ccc(ON2C(=O)C(O)Oc3cc(OC)ccc32)c(OC)c1</smiles><smiles>COc1ccc(N(O)C(=O)/C=N/F)c(O)c1</smiles><smiles>N#CC=CC=[NH2+]</smiles><smiles>COC</smiles><smiles>O=C(CCl)N(O)c1ccc(I)cc1O</smiles><smiles>COc1ccc(NC(=O)C=O)c(O)c1</smiles><smiles>[R]N=CC(=N[R])N(O)c1ccc(OC)cc1O</smiles><smiles>COC</smiles><smiles>Cc1ccc(N(O)C(=O)C(O)SF)c(O)c1</smiles><smiles>[BiH]</smiles><smiles>COC</smiles><smiles>[R]SC(O)C(=O)Nc1ccc(C)cc1O</smiles>

Scheme 5. Reactions of DIMBOA with amines and thiols..$^{27,54,55}$ 
values. Hemithioacetals of DIMBOA and HMBOA open forms were isolated in low yields from the reaction with ethanethiol, but were shown via ${ }^{1} \mathrm{H}$ NMR to be the predominant form in solution with an excess of thiol..$^{27}$ The pattern of chemical shifts shows that the oxo-cyclo ringchain tautomerism is trapped in the open form by thiolate attack on the aldehyde carbon. The fact that the lactam is the major isolated product from this reaction is presumably due to the instability of the hemithioacetal function in basic medium. Reduction of DIMBOA to HMBOA by thiols is considered to be a consequence of the reactivity of the nitrenium ion as discussed in the next section. A tentative mechanism for such a reduction is presented in Scheme 7.

\subsection{Electrophilicity of the nitrenium ion}

The nitrogen atom can also be an electrophilic site in the benzoxazinone skeleton, especially upon elimination of the $\mathrm{N}$-substituent group and formation of a nitrenium ion. A comprehensive study on this reactivity was done with 4-acetoxy-7-methoxy-2H-1,4-benzoxazin-3(4H)-one (4- $N$-OAc-D-DIMBOA, where D- refers to 2-dehydroxy-), referred to as AMBOA in the original article, a synthetic derivative of 2-dehydroxy DIMBOA. ${ }^{41}$ After heterolytic $\mathrm{N}-\mathrm{O}$ cleavage, elimination of the acetoxy group at position 4 generates a nitrenium ion, which behaves as a multicentered electrophile as shown in Scheme 6. Reactions with nucleophiles such as phenols, anilines, thiols, pyrroles, indoles, diazoles and pyridine gave rise to products from nucleophilic attack on positions $2,4,5,6$, and 7 , with regioselectivities varying according to the nucleophilic atom involved (carbon, nitrogen, or sulfur). Furthermore, 4- $N$-OAc-D-DIMBOA reacts with amino acid derivatives such as protected tyrosine, histidine, and tryptophan. Adducts with guanine (but not other nucleotides) were observed after incubation of 4-N-OAc-D-DIMBOA with calf thymus DNA followed by enzymatic hydrolysis, and direct incubation with either 5'-deoxyguanylic or 5 '-guanylic acids. This reaction accounted for as much as $4 \%$ of total guanine residues present under the experimental conditions, and occurred between the position 8 of guanine and the BXD nitrogen atom. ${ }^{56}$

It is important to note that all reactions described for 4- $N$-OAc-D-DIMBOA are associated with the closed form of this derivative, since the absence of a hydroxy group at position 2 eliminates the oxo-cyclo ring-chain tautomerism present in other benzoxazinones. However, introduction of a 2-hydroxy group enhanced the reactivity of the 4-acetoxy derivative towards nucleophiles. Moreover, 4-N-OAc-D-DIBOA, which lacks the 7-OMe group, showed reduced yields in reaction with phenol, suggesting that an electron donating group at position 7 can facilitate $\mathrm{N}-\mathrm{O}$ heterolytic cleavage. ${ }^{41}$ Despite being synthetic BXD derivatives, 4- $N$-OAc-D-DIMBOA and its analogs might be generated from natural BXD hydroxamic acids after activation by acyltransferases, which are important enzymes in xenobiotic metabolism. After incubation with the S-9 fraction from rat livers, the supernatant of a $9000 \times$ g centrifugation containing high levels of enzymes of xenobiotic metabolism, D-DIMBOA (the hydroxamic

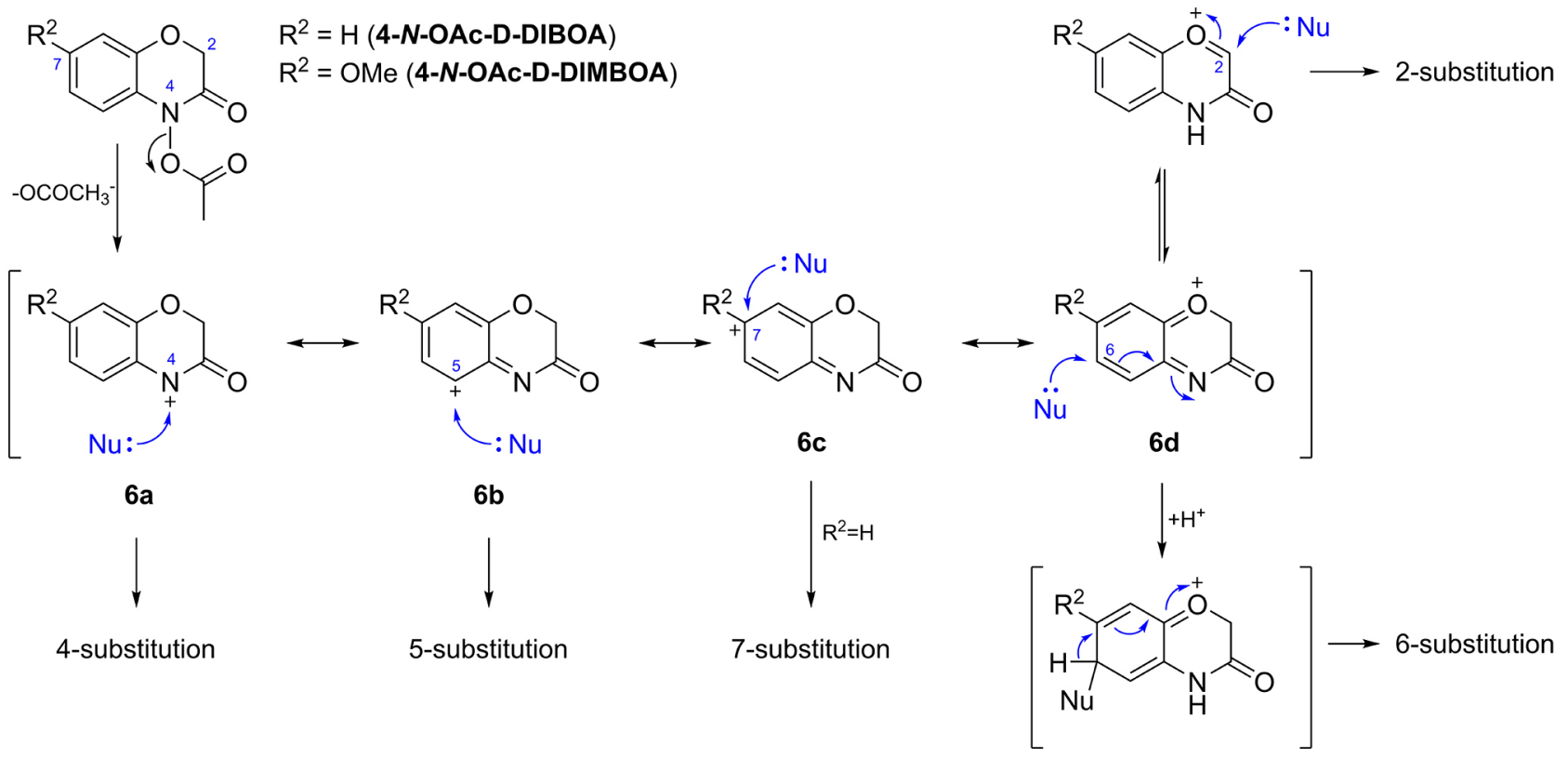




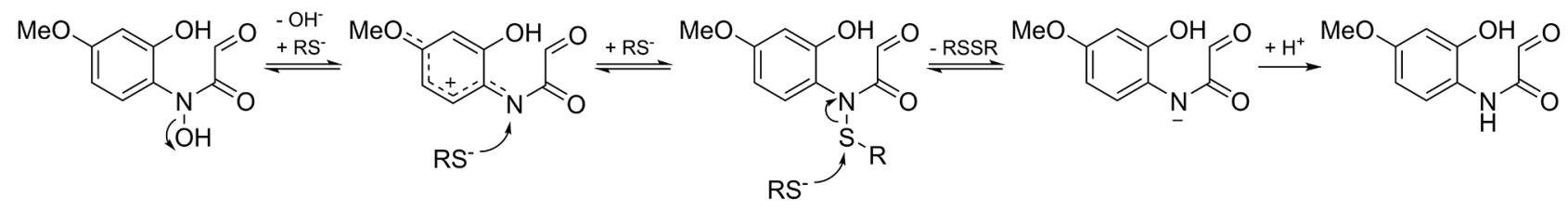

Scheme 7. Proposed mechanism for the reduction of DIMBOA to HMBOA by thiols.

acid analog of 4- $N$-OAc-D-DIMBOA) showed increased mutagenic activity, suggesting the enhancement of its reactivity by metabolic activation. ${ }^{57}$

Formation of nitrenium ions is also involved in hydroxamic acid reactions in strongly acidic medium. DIBOA and DIMBOA analogs lacking the 2-hydroxy group (D-DIBOA and D-DIMBOA, respectively) react with $\mathrm{HCl}$ forming mainly the 7- and 5-chloro substituted products, respectively. ${ }^{58}$ Such reactions are supposed to occur via nitrenium ion intermediates shown in Scheme 6, but in this case the strongly acidic medium causes the protonation of the hydroxamic acid hydroxy group, making it a better leaving group and facilitating $\mathrm{N}-\mathrm{O}$ heterolytic cleavage.

Reduction of DIMBOA to HMBOA by thiols, mentioned in the previous section, is proposed to involve the formation of nitrenium ions, as shown in Scheme 7. This mechanism is supported by the striking increase in the rate of reduction to lactam when the 7-OMe group is present, compared to other analogs..$^{27}$ Such substituents can stabilize the positive charge on the nitrogen atom by resonance, facilitating the following nucleophilic attack from the thiolate. In theory, the formation of the nitrenium ion could occur on either the closed or open forms of the hydroxamic acid, as shown in Scheme 5. However, the participation of the 7-OMe group suggests that the nitrogen atom is conjugated with the ring. This situation may be more favored in the benzoxazinone open form, since without the constraint from the heterocycle, the nitrogen lone electron pair can overlap the aromatic $\pi$-system more efficiently. Indeed, DIMBOA analogs unable to undergo oxo-cyclo ring-chain tautomerism, such as 2-dehydroxy and methyl acetal derivatives and the analog lacking the heterocyclic oxygen, do not easily react with mercaptoethanol, requiring harsh conditions to provide only small yields of the lactam. ${ }^{27}$

Reactions between DIMBOA and thiols, including mercaptoethanol and glutathione, an important thiol nucleophile in biological systems, have been investigated by Dixon et al. ${ }^{59}$ In this case, however, lactams were not the major observed product, but rather spirocyclic adducts with either one or two thiol equivalents were formed (Scheme 8). Such adducts had their aromatic rings remarkably altered, as shown by ${ }^{1} \mathrm{H}$ NMR. The reaction was suggested to involve an $o$-imidoquinone derivative originating from the loss of water from DIMBOA, which can be attacked by the thiol at position 5. Subsequently, the aldehyde carbon can be attacked either by water, forming a hydrate, or another thiol molecule, forming a hemithioacetal. Both compounds then undergo an internal nucleophilic attack forming a 5-member ring spiro-fused to the original BXD 6-member ring. DIMBOA also irreversibly formed an adduct with a model enzyme (Arabidopsis thaliana glutathione transferase AtGSTF8) targeting a single cysteine residue, as confirmed by tryptic digestion and MS/MS sequencing. Efficient reactions between DIMBOA and thiols suggest that BXDs can potentially cause damage to target organisms by depleting glutathione levels, but more studies are necessary to confirm such pro-oxidant activity. Although some DIMBOA reduction to HMBOA was observed, the products from these reactions with thiols were notably

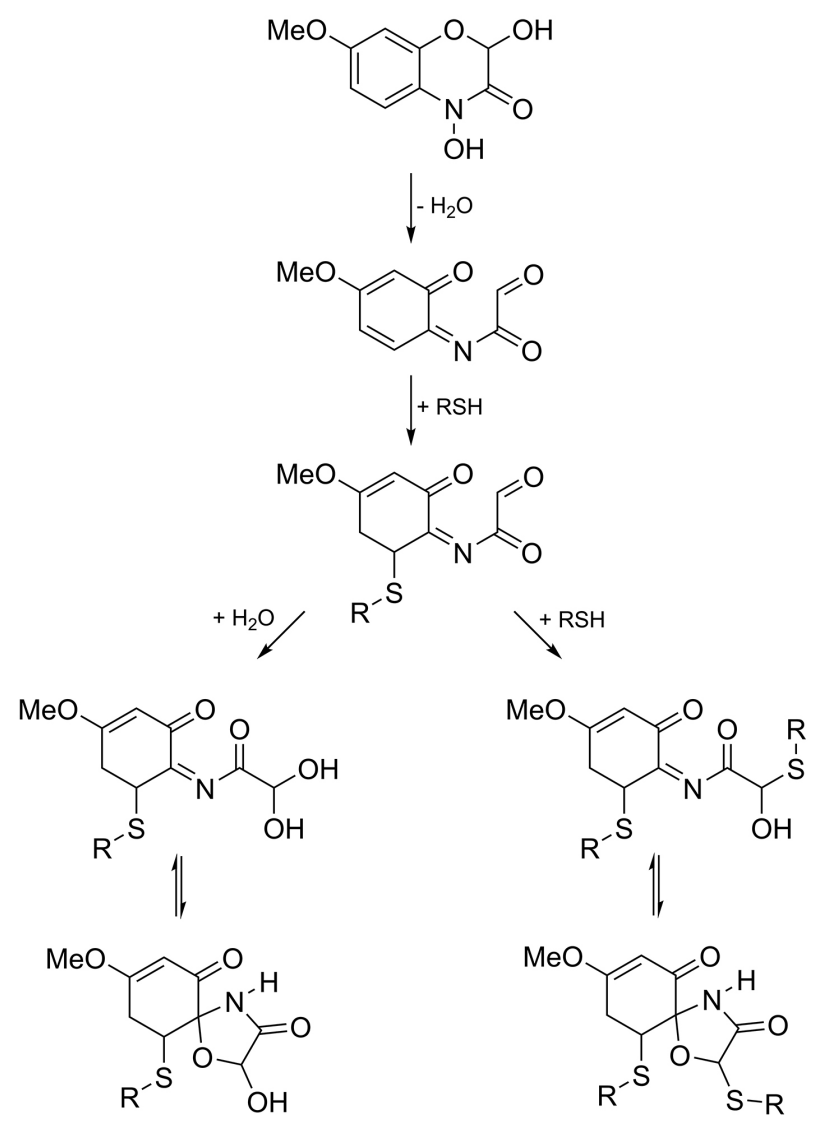

Scheme 8. DIMBOA spiro adduct formation with thiols (adapted from Dixon et al. .). ${ }^{59}$ 
different from the ones obtained previously. ${ }^{27,55}$ Formation of spirocyclic adducts with thiols could have been favored by the solvent system used (45\% acetonitrile in aqueous buffer). Mixtures of water and organic solvents can modify the $\mathrm{pH}$ from corresponding buffers and lead to altered $\mathrm{pK}_{\mathrm{a}}$ values of dissolved acids as well as cause solvation effects, ${ }^{60}$ all factors that could influence the reactivity of DIMBOA and thiols in solution.

Interestingly, the canonical structures proposed for the nitrenium ion in Scheme 6 include an $o$-imidoquinone derivative (6d). Reactions via the nitrenium ion are supposed to involve BXDs in a closed, positively charged form, whereas reactions via neutral imidoquinones such as 3 (Scheme 3) should involve open form, neutral species. However, due to oxo-cyclo ring-chain tautomerism, the products from both reaction pathways are indistinguishable. Indeed, imidoquinones are expected to react with nucleophiles at different sites, including the nitrogen atom, depending on conditions and the nature of the nucleophile used. ${ }^{41,61}$ Even DIMBOA, with a poor leaving group at the nitrogen atom, can react following a nitrenium/imidoquinone pathway, ${ }^{58,59}$ suggesting that formation of these intermediates is not only dependent on the $N$-substituent, but also the conditions used. It can be assumed that reactions via the nitrenium ion or neutral $o$-imidoquinone are similar and either can be favored under different conditions. Their competition seems to be dictated by $\mathrm{pH}$ conditions and structural features, such as the possibility of ring opening and stereoelectronic effects that might assist $\mathrm{N}-\mathrm{O}$ heterolytic cleavage with elimination of a neutral or negatively charged fragment.

\subsection{Coordination properties of hydroxamic acids}

Hydroxamic acids and other compounds known collectively as siderophores are well known for their metal ion chelating properties, and are used by microorganisms, fungi, and plants in order to sequester and solubilize $\mathrm{Fe}^{\mathrm{III}}$ from the environment. Siderophores are also used by pathogenic fungi and bacteria to scavenge iron from their host organisms. After coordination to iron, siderophore complexes are taken up by microbial cells via specific transport systems present in the outer membrane and delivered to the cytoplasm..$^{62,63}$ Sideromycins, antibiotics covalently linked to siderophore moieties, take advantage of this recognition system and are potent naturally occurring antibiotics. The active transport of such compounds greatly reduces their minimal inhibitory concentration by enhancing delivery to cellular targets. ${ }^{64}$

Despite not being included in the classical examples of phytosiderophores, BXDs with a hydroxamic acid function can potentially chelate metals and exert biological effects related to siderophore activity. The ability to form complexes with $\mathrm{Fe}^{\mathrm{III}}$ has been exploited by colorimetric methods for the detection and quantification of hydroxamic acids in BXD studies. ${ }^{65}$ Other than iron, complexation of DIMBOA with $\mathrm{Zn}^{\mathrm{II}}, \mathrm{Cu}^{\mathrm{II}}$, and $\mathrm{Mn}^{\mathrm{II}}$ has also been observed. At the concentration levels found in plants, metal cations are complexed more by DIMBOA than by citric and malic acid, two abundant chelators from maize exudates. ${ }^{66,67}$ As investigated by ESI-MS, lactams and methyl derivatives of hydroxamic acids do not form complexes with $\mathrm{Fe}^{\mathrm{III}} .68$ Interestingly, glucosides such as DIMBOA-Glc and DIBOA-Glc have also been shown to coordinate to $\mathrm{Fe}^{\mathrm{III}}$, ${ }^{55,69}$ and the similar stability constants for $\mathrm{Fe}^{\mathrm{III}}$ complexes with DIMBOA and DIMBOA-Glc suggest that the presence of the sugar moiety has little effect on BXD coordinating properties. ${ }^{65}$

Due to their ability to chelate metals, BXDs exuded by plant roots have been proposed to play a role in nutrient uptake and defense against metal toxicity. Roots of maize, wheat, and rye seedlings greatly vary in the levels of hydroxamic acids exuded in response to $\mathrm{Fe}^{\mathrm{III}}$ content in the growth medium..$^{70,71}$ Iron(III) complexes with DIBOAGlc and DIMBOA-Glc are taken up by maize roots, but also by rice and oat which do not produce hydroxamic acids. Exogenous BXD glucosides absorbed by roots of rice and oat as iron complexes can be detected in the shoots, suggesting the transport of these compounds between organs. In the leaves of iron-deficient maize, administration of $\mathrm{Fe}^{\mathrm{III}}$ hydroxamate complexes alleviates chlorotic symptoms and increases chlorophyll content of maize. ${ }^{72}$ These results suggest that hydroxamic acids might be involved in iron uptake by cereals and could also be incorporated by other plants. ${ }^{73}$

DIMBOA might also serve as a defense against aluminum toxicity in plants. Upon $\mathrm{Al}^{\mathrm{III}}$ treatment, maize lines resistant to aluminum increased BXD levels in roots, especially in root tips, the region most sensitive to $\mathrm{Al}^{\mathrm{II}}$ toxic effects. DIMBOA also reduced callose accumulation (an indicator of cell damage that is a well described response to $\mathrm{Al}$ toxicity) in roots of maize lines susceptible to $\mathrm{Al}{ }^{\mathrm{III}}$ that were treated with this metal. Binding of $\mathrm{Al}^{\mathrm{III}}$ to DIMBOA was measured by fluorescence quenching. ${ }^{74}$

However, the importance of metal complexation by BXD hydroxamic acids in natural contexts is not yet well understood. More detailed studies are needed in order to confirm the role of BXDs in the uptake of iron and possibly other metals by plants, and distinguish the importance of their apparent siderophore behavior from their associated antimicrobial activities. It is important to note that coordination to metal cations might also be relevant to BXD glucosides, normally considered to be devoid of any toxicity or biological 
activity. The inhibition of enzymatic activity by BXD hydroxamic acids and derivatives could also be promoted by the chelation of such compounds to metal cofactors. ${ }^{75}$

\subsection{Benzoxazolinones and related compounds}

Even though benzoxazolinones are implicated in many biological activities, their modes of action and structureactivity relationships are even less studied than those of benzoxazinones. Structurally, benzoxazolinones resemble important signaling compounds such as melatonin, serotonin, and tryptophan. Effects on the central nervous system have been suggested to explain the stimulation of the reproductive system and appetite loss caused by MBOA in mammals. ${ }^{76}$ In plants, benzoxazolinones are able to inhibit auxin-induced growth in roots and coleoptiles, presumably by modifying the binding affinity of auxins to receptor sites. ${ }^{77-79}$ Even though the exact molecular mechanisms are not known, these compounds are suggested to be involved in phototropism in maize and possibly in allelopathic activities towards competing plants. The possible effects of benzoxazolinones on signaling have not been well explored in insects or microorganisms.

Benzoxazolinone metabolism by soil microorganisms has been relatively well studied within the context of the allelopathic effects of BXDs. ${ }^{80}$ Transformation products such as aminophenols, aminophenoxazinones, acetamides, and malonamic acid derivatives have been characterized and are presented in Scheme 9. The aminophenoxazinones APO and AMPO are suggested to play a role in allelopathy ${ }^{75,81,82}$ and possibly in interactions with other microorganisms, nematodes, and root herbivores, but these compounds could also arise from non-BXD progenitors.

\subsection{Physico-chemical properties}

Although not directly involved in the mechanisms of toxicity, some of the physico-chemical properties of
BXDs are expected to influence their overall activity. For example, the diversity of ring and heteroatom substitution patterns found in BXDs modulates their lipophilicity, which can greatly influence their diffusion across cellular membranes. Lipophilicity also dictates the ability of BXDs released into the soil to affect competing plants and root herbivores. In "soil TLC" experiments, which determine how compounds diffuse through soil when carried by water, DIMBOA showed mobility intermediate between those of low-mobility phenolic acids and other high-mobility compounds such as vanillin and coumarin,${ }^{83}$ but no other BXDs were compared. BOA and MBOA showed low mobility when applied on the soil surface, being mostly recovered (71 and 97\%, respectively) in the top $1 \mathrm{~cm}$ of the soil profiles. ${ }^{84}$

Lipophilicity also seems to influence the biological activities of BXDs, as shown by the structure-activity relationship studies discussed on more detail on the following section. The substitution patterns of BXDs are also expected to control their acidity, which can be an important factor in the solubility, chelating properties, and diffusion under different $\mathrm{pH}$ conditions.

\section{Structure-Activity Relationship Studies}

Extensive work has been performed in order to rationalize the influence of BXD structure on activity against a wide range of organisms. These studies have been greatly aided by the established synthetic routes to BXDs enabling access to non-natural analogs that differ in their modes of action. Therefore, a critical evaluation of each aspect of BXD reactivity in connection to different biological activities is possible. Structure-activity relationship studies are discussed within the context of BXD biological activities in this section and interpreted according to the modes of action presented in the previous sections. Some relevant structures used for these experiments are shown in Scheme 10, including natural and non-natural BXD<smiles>[R]c1ccc(N)c(O)c1</smiles>

aminophenols<smiles>[R]c1ccc(NC(C)=O)c(O)c1</smiles>

acetamides<smiles>[R]c1ccc(NC(=O)CC(=O)O)c(O)c1</smiles>

malonamic acid derivatives<smiles>Nc1cc2nc3ccccc3oc-2cc1=O</smiles>

APO<smiles>COc1ccc2nc3cc(N)c(=O)cc-3oc2c1</smiles>

AMPO

Scheme 9. Transformation products of benzoxazolinones in soil. ${ }^{80,81}$ 
analogs, as well as aminophenoxazinones, BXD soil metabolites tested for phytotoxicity. A comprehensive discussion of the biological activities of BXDs, their underlying physiological mechanisms, and responses by each organism is out of the scope of the present review. Rather, we focus on studies comparing several structurallyrelated BXD derivatives under the same conditions and describe general trends for the relationships between BXD structural features and biological activities. Such general trends for activity against insects, microorganisms, algae and plants are summarized on Table 1. The individual influence of these features is discussed in the following sections.

\subsection{Enzymatic inhibition}

Unfortunately, no comprehensive in vitro studies have been carried out to compare the inhibition of individual<smiles>[R3]c1ccc2c(c1)OC([R])C(=O)N2[R]</smiles>

benzoxazinones

\begin{tabular}{cccc}
\hline Benzoxazinone & $\mathbf{R}^{1}$ & $\mathbf{R}^{2}$ & $\mathbf{R}^{3}$ \\
\hline DIBOA & $\mathrm{OH}$ & $\mathrm{OH}$ & $\mathrm{H}$ \\
D-DIBOA & $\mathrm{H}$ & $\mathrm{OH}$ & $\mathrm{H}$ \\
2-O-Me-DIBOA & $\mathrm{OMe}$ & $\mathrm{OH}$ & $\mathrm{H}$ \\
4-N-OAc-DIBOA & $\mathrm{OH}$ & $\mathrm{OAC}$ & $\mathrm{H}$ \\
4-N-OAc-D-DIBOA & $\mathrm{H}$ & $\mathrm{OAc}$ & $\mathrm{H}$ \\
DIMBOA & $\mathrm{OH}$ & $\mathrm{OH}$ & $\mathrm{OMe}$ \\
D-DIMBOA & $\mathrm{H}$ & $\mathrm{OH}$ & $\mathrm{OMe}$ \\
2-O-Me-DIMBOA & $\mathrm{OMe}$ & $\mathrm{OH}$ & $\mathrm{OMe}$ \\
4-N-OAc-D-DIMBOA & $\mathrm{H}$ & $\mathrm{OAc}$ & $\mathrm{OMe}$ \\
HBOA & $\mathrm{OH}$ & $\mathrm{H}$ & $\mathrm{H}$ \\
D-HBOA & $\mathrm{H}$ & $\mathrm{H}$ & $\mathrm{H}$ \\
HMBOA & $\mathrm{OH}$ & $\mathrm{H}$ & $\mathrm{OMe}$ \\
D-HMBOA & $\mathrm{H}$ & $\mathrm{H}$ & $\mathrm{OMe}$ \\
\hline
\end{tabular}<smiles>[R]c1ccc2[nH]c(=O)oc2c1</smiles>

benzoxazolinones

\begin{tabular}{cc}
\hline Benzoxazolinone & $\mathbf{R}$ \\
\hline BOA & $\mathrm{H}$ \\
MBOA & $\mathrm{OMe}$ \\
6-OH-BOA & $\mathrm{OH}$ \\
\hline
\end{tabular}

enzymes by a range of BXD structures. However, the comparison of experiments with a few BXDs can give us hints about the mechanisms by which these compounds act on enzymes.

DIMBOA was shown to inhibit papain, a cysteine protease, by reacting with a cysteine residue in the active site. ${ }^{85}$ Although D-DIMBOA, an analog lacking a lactol moiety, inhibited papain in a similar fashion, HMBOA, a lactam, did not display inhibition. Since the former compound does not undergo oxo-cyclo ring-chain tautomerism and the latter does, the electrophilicity of the open form does not seem to play a role in enzyme inhibition in this case. Instead, the presence of a better leaving group as the $N$-substituent seems to be responsible for this activity, suggested to involve the reaction between the cysteine thiol group and the nitrogen atom via a nitrenium/imidoquinone derivative. Indeed, the inhibition was reversed by addition of dithiothreitol, which is consistent with the reduction of DIMBOA to HMBOA by<smiles>[R]c1ccc2c(c1)CC([R])C(=O)N2[R]</smiles>

quinolinone derivatives<smiles>[R]c1ccc2c(c1)SC([R])C(=O)N2[R]</smiles>

benzothiazinone derivatives<smiles>[R3]c1ccc(NC(=O)C=O)c(OC)c1</smiles>

open chain derivatives<smiles>[R]Nc1cc2nc3ccc([R])cc3oc-2cc1=O</smiles>
aminophenoxazinones

\begin{tabular}{ccc}
\hline Aminophenoxazinone & $\mathbf{R}^{1}$ & $\mathbf{R}^{2}$ \\
\hline APO & $\mathrm{H}$ & $\mathrm{H}$ \\
AAPO & $\mathrm{OAC}$ & $\mathrm{H}$ \\
AMPO & $\mathrm{H}$ & $\mathrm{OMe}$ \\
AAMPO & $\mathrm{OAC}$ & $\mathrm{OMe}$ \\
AHPO & $\mathrm{H}$ & $\mathrm{OH}$ \\
\hline
\end{tabular}

Scheme 10. Compounds used in structure-activity relationship studies. For consistency, some names have been modified from those used in the original references. 
Table 1. Summary of the influence of structural features of benzoxazinones on biological activities towards target organisms

\begin{tabular}{|c|c|c|c|c|}
\hline \multirow{2}{*}{ Structural feature } & \multicolumn{4}{|c|}{ Target organism } \\
\hline & Insects (toxicity) & Microorganisms & Algae & Plants \\
\hline Capacity to undergo ring opening & $\uparrow$ & $*$ & $*$ & $\downarrow$ \\
\hline Presence of $N-\mathrm{OH}$ (compared to $N-\mathrm{H}$ ) & $\uparrow$ & $\uparrow$ & $\uparrow$ & $\uparrow$ \\
\hline Presence of $N$-OAc (compared to $N-\mathrm{OH}$ ) & n.e. & - & $\downarrow$ & $*$ \\
\hline Electron-donating group at position 7 & $\uparrow$ & $\uparrow$ & $*$ & - \\
\hline Presence of sulfur as heteroatom (benzothiazinones) & $\uparrow$ & n.e. & n.e. & n.e. \\
\hline Presence of glucose moiety & $\downarrow$ & $\downarrow$ & $\downarrow$ & - \\
\hline Enhanced lipophilicity & $\downarrow$ & n.e. & $\uparrow$ & $*$ \\
\hline
\end{tabular}

$\uparrow:$ activity increases; $\downarrow$ : activity decreases; -: activity is not affected; *: activity increases or decreases according to BXD structure or specific target; n.e.: not evaluated.

reaction with thiols (Scheme 7). DIMBOA was also observed to inhibit $\alpha$-chymotrypsin, a serine protease. ${ }^{86}$ In this case, however, 2-O-Me-DIMBOA did not inhibit this enzyme, indicating that ring opening is important for activity. The authors proposed that the $\alpha$-oxo-aldehyde function in the $\mathrm{BXD}$ open form reacts with the serine residue in the active site, causing the observed inhibition.

These studies indicate that even within the same enzyme class (digestive proteases), BXDs may cause inhibition by different modes of action depending on their target. The aldehyde and nitrogen electrophilic sites in the BXD structure seem to have differential reactivities depending whether the nucleophile is a thiol, hydroxyl, or amine group, indicating that enzyme inhibition mechanisms depends on the residues at the active site as well as other conditions that modulate BXD reactivity patterns. The inhibition of digestive proteolytic enzymes is normally associated to the overall antifeedant and toxic effects of BXDs towards herbivores. Considering that insects with an alkaline gut lumen (such as most lepidopterans) rely mainly on serine-based proteinases, while insects with acidic guts (such as coleopterans) rely on thiol-based proteinases, ${ }^{87}$ distinct chemical modes of action and molecular targets could become more relevant in different target insects, even though the physiological mode of action (inhibition of proteinases) can be considered the same. The influence of BXDs on enzymatic activity might also be a consequence of interactions outside the enzyme active site. The effects of BXDs on plant enzymes have been discussed elsewhere. ${ }^{81}$ Unfortunately, neither with plant nor animal enzymes has BXD attack on particular residues been verified by sequencing of the covalently-bound BXD-protein adduct.

\subsection{Activities against insects}

The effect of BXD analogs in inhibiting the growth of the lepidopteran chewing herbivore Ostrinia nubilalis was compared ${ }^{88}$ Among the natural BXDs tested, DIMBOA was the most toxic, followed by DIBOA and DIM $_{2}$ BOA. Lactams such as HMBOA and HBOA did not significantly inhibit growth, and neither did hydroxamic acids unable to undergo ring opening (2-dehydroxy, methyl acetals, and quinolinone derivatives). No clear correlation was found between toxicity and either degradation rates to benzoxazinones or rates of reduction to lactam by thiols. The involvement of benzoxazolinones formed by degradation during the experiment was not considered important, since MBOA required concentrations 10-20 times higher than DIMBOA to exert comparable toxic effects. However, it is important to note that the high $\mathrm{pH}$ of the caterpillar gut (around 9 in Spodoptera frugiperda) ${ }^{89}$ has an important effect on benzoxazinone stability. Analogs that degrade too quickly in such conditions might not persist long enough to manifest toxicity. Natural hydroxamic acids like DIMBOA, however, are suggested to show a balance between stability and reactivity that allows them to have considerable activity against herbivores. Although the range of compounds tested in this study was not wide enough to allow for more general interpretations, it seems that both the hydroxamic acid function and the possibility of ring opening are important for activity against caterpillars. However, either of these features alone does not seem to be sufficient, since lactams and analogs with the lactol function absent or blocked did not show activities. Since lactams can still become reactive aldehydes by ring opening, and compounds without a C-2 lactol function can still form metal complexes, these two modes of action do not seem to be critical for the observed activity. On the other hand, the simultaneous presence of a better leaving group on the nitrogen atom and the possibility of ring opening could facilitate the formation of reactive intermediates like nitrenium ion/imidoquinone derivatives. In fact, the $\mathrm{N}$-O-methylated derivative HDMBOA is considered to be even more toxic to caterpillars than DIMBOA, ${ }^{12}$ which 
supports that this mechanism might play an important role on inhibiting insect growth.

BXDs display both antifeedant and insecticidal activities towards a wide range of aphid species. ${ }^{1}$ Escobar et al..$^{90}$ compared the antifeedant and insecticidal activities of various BXD analogs towards the aphid Sitobion avenae. In pairwise comparisons of benzoxazinones, the presence of a 7-OMe electron-donating group, the presence of a sulfur instead of oxygen as the heteroatom (benzothiazinone derivatives), and the possibility of ring opening were shown to increase antifeedant and mortality indices. Such a clear trend was not observed for comparisons between lactams and hydroxamic acids. Interestingly, antifeedant and insecticidal activities do not seem to be strictly correlated, suggesting that the underlying mechanisms for the two activities do not completely overlap. For example, among the tested benzoxazolinones MBOA showed high deterrence levels but low toxicity, while 6-OH-BOA showed comparatively higher mortality but lower deterrence. HMBOA and its open chain analog with a protected phenol gave similar mortality indices towards aphids, suggesting that the electrophilicity of the open form might be important for toxicity, but the antifeedant activity of the latter was much higher. In general, benzothiazinones showed enhanced antifeedant and mortality indices, even for structures with a protected or absent lactol group. For other BXD analogs, however, toxicity seems to be enhanced by the possibility of ring opening and presence of a hydroxamic acid function, similarly to the activity observed for $O$. nubilalis. Likewise, benzoxazolinones tended also to be less toxic to $S$. avenae than benzoxazinones.

In a comparison of the antifeedant activity of BXD analogs towards a second aphid species, Rhopalosiphum padi, ${ }^{11}$ the possibility of ring opening seemed to contribute to activity, and hydroxamic acids were more active than lactams. However, more lipophilic derivatives had lower activities, suggesting that lipophilicity may reduce diffusion of compounds into the phloem fed on by aphids or subsequently into insect tissues. In this experiment, however, DIBOA was more deterrent than DIMBOA, in contrast to the experiment with $S$. avenae..$^{90}$ It is important to point out that the two aphid experiments differ in their protocols. The $S$. avenae experiment used BXDs in artificial diets (sucrose solution in sachets), whereas the $R$. padi experiment involved BXDs sprayed on barley leaves. It is not clear how efficiently BXDs sprayed on the leaf surface diffuse into cells, whether they are metabolized by the plant, and whether their tissue distribution actually mimics what an aphid would find in a BXD containing plant. On the other hand, the behavior of aphids in relation to BXDs might be altered by feeding on artificial diets.
Due to the compartmentalization of BXDs in plants as glucosides and their activation by $\beta$-glucosidases, the feeding behavior of insects likely influences the extent to which they are exposed to such compounds. Piercing and sucking insects such as phloem-feeding aphids could potentially avoid BXD activation by avoiding contact with plant glucosidases. However, since aphids are highly dependent on microbial symbionts, any antimicrobial effect of BXDs or their glucosides could also contribute to their activities on these insects. These make the study of BXD effects and mode(s) of action in sucking insects more challenging. In addition, the glucosides DIMBOA-Glc and HDMBOA-Glc showed antifeedant and insecticidal activities towards aphids, ${ }^{92}$ suggesting that these activities derived from the BXD glucosides themselves or that the aphids are able to hydrolyze BXD glucosides with their own enzymes.

\subsection{Activity against microorganisms}

The antimicrobial activities of BXD hydroxamic acids were assessed against Staphylococcus aureus, Escherichia coli, and Candida albicans. ${ }^{93} \mathrm{~A}$ higher electron-donating character of the 7-substituent increased activity, whereas the possibility of ring opening did not seem to have a consistent influence on activity. This indicates that the electrophilicity of the open form and the degradation to benzoxazolinones are not important for antimicrobial activity. In another study investigating the activity of different BXD analogs towards C. albicans,${ }^{94}$ hydroxamic acids showed higher antifungal activity than lactams, while glucosides had no activity. Surprisingly, 4- $N$-OAc-DIBOA displayed similar antifungal activity to DIBOA, suggesting that the electrophilicity of the nitrenium ion does not contribute significantly to this activity. When evaluated with $C$. albicans, the 2-dehydroxy derivatives of DIBOA and DIMBOA showed higher activities than these lactols. Antifungal (and possibly antibacterial) activities seem to be highly dependent on the presence of a hydroxamic acid function. This suggests a mechanism in which these compounds exert toxicity due to chelation properties and/ or are actively incorporated by microbial cells due to their siderophore-like nature. However, as DIBOA-Glc and DIMBOA-Glc had no activity, possibly due to their high hydrophilicity, passive diffusion of BXDs through microbial membranes should also be considered.

Analogs of the benzoxazolinone BOA with different 6-substituents were evaluated against $S$. aureus, E. coli, and $C$. albicans. ${ }^{95}$ In general, the fungus $C$. albicans was more sensitive to structural changes compared to the bacteria, and showed inhibitory concentrations on the 
same range as those observed for BXD hydroxamic acids. Antifungal activity increased with higher lipophilicity and was dependent on electronic effects from substituents in the aromatic ring. Activity increased with polarization of the $\mathrm{N}-\mathrm{H}$ bond, which is promoted by both electron-donor (such as methoxy) and electron-acceptor (such as nitro) groups at position 6 .

\subsection{Activity against plants}

The antialgal activity of BXD analogs was investigated against Chlorella xantella. ${ }^{94}$ Due to its similarity with higher plants, this alga has been recommended as a model for phytotoxicity evaluation. The blocking of ring opening did not consistently affect antialgal activity, which was similar for 2-dehydroxy derivatives and lactols, implying that the electrophilicity of the open form is not essential to the observed antialgal activities. Glucosides such as DIBOA-Glc and DIMBOA-Glc had no activity, probably due to their high hydrophilicity. Among aglucone analogs, activity increased with the increase of lipophilicity, but was not clearly correlated with the electronic effects of aromatic ring substituents. The presence of a 4- $\mathrm{N}$-acetoxy group decreased activity, suggesting that antialgal activity does not depend on nitrenium ion electrophilicity.

Phytotoxicity was evaluated for a range of concentrations of natural and synthetic benzoxazinones, benzoxazolinones, and their soil degradation products against wheat, onion, cress, lettuce and tomato. ${ }^{96}$ The root growth of all species was strongly inhibited by some of the tested BXDs, except for wheat, which was only moderately inhibited, suggesting that this species is not affected by allelopathic interactions involving BXDs. The benzoxazolinones BOA and MBOA were only slightly inhibitory even at the highest tested concentrations, and even promoted root growth in wheat. Thus if DIBOA and DIMBOA degraded to the corresponding benzoxazolinones during the experiment, their toxicity may have been underestimated. For most species, DIBOA and DIBOA-Glc gave similar root growth inhibition profiles, suggesting that seedlings are able to incorporate both and possibly hydrolyze glucosides with their own glucosidases. Among natural BXDs, the hydroxamic acids DIBOA and DIMBOA were toxic and the lactams HBOA and HMBOA were not. However, the 2-dehydroxy derivatives of both hydroxamic acids and lactams showed higher phytotoxicity, meaning that ring opening is not involved in such activity, and the presence of a hydroxamic acid function might contribute, but is not essential to activity. The acetyl derivative $4-\mathrm{N}$-OAcD-DIBOA was one of the most active compounds, with considerable toxicity even in lower concentrations.
On the other hand, lower toxicity was observed for 4- $N$-OAc-D-DIMBOA when compared to D-DIMBOA. It seems that the influence of 4- $N$-substituents may not be strictly correlated to their stereoelectronic effects, but also to other substituents and the overall lipophilic character of the molecule. Among the degradation products, only the aminophenoxazinone APO showed high activity. The inhibitory effects of aminophenoxazinones seem to increase as the lipophilicity of the compound decreases. The same compounds were tested and similar results were obtained for the weeds Avena fatua (wild oat) and Lolium rigidum (rigid ryegrass). ${ }^{97}$ Both species belong to the family Poaceae, suggesting that the resistance to BXDs observed in wheat is not widespread in grasses. In another study on L. sativum, similar results were observed for root growth and $\alpha$-amylase inhibition, which were correlated. ${ }^{82}$

The phytotoxicity of D-DIBOA has been further optimized by testing synthetic analogs with different substitution patterns at positions $2,4,6,7$, and 8 . Quantitative structure-activity relationship (QSAR) analysis revealed optimal ranges for parameters such as lipophilicity (log P), molecular volume, dipole moment, and polarizability, as in studies for design of drugs and agrochemicals. ${ }^{98-100}$ The influence of such parameters on phytotoxicity indicates that, beside reactivity, transport phenomena and the ability to reach the target site have critical influences on the overall biological activity observed for BXDs.

It is important to point out that the allelopathic effects of BXDs have only been investigated for a few plant species to date and so broad generalizations are still unwarranted. Any factor that alters the mechanisms by which BXDs are absorbed, distributed, and metabolized by plants may influence their overall allelopathic activity.

\section{Conclusions}

Benzoxazinoids are versatile plant chemical defenses showing activities towards a wide range of target organisms. The unique structural features of this class of compounds give rise to many possible modes of action that could be responsible for their well-documented activities against insects, microorganisms, and competing plants. In addition, the mixtures of BXD structures present in individual plants and the changing pattern in response to enemies and competitors may also contribute to the defensive roles of these secondary metabolites.

The variety of chemical properties and reactivities of BXDs make these compounds extremely interesting from the evolutionary point of view, but makes the study of their modes of action quite challenging. The stability 
and reactivity of BXDs are highly dependent on their structures and on conditions such as $\mathrm{pH}$ and temperature. However, previous literature has commonly generalized the biological activities of BXDs attributing the same potential underlying mechanisms to all of them regardless of the target organism and observed effect. In light of the structure-activity relationship studies discussed, the modes of action seem to differ among the biological activities tested. Each activity is not necessarily a consequence of one chemical aspect alone, and each target organism is not necessarily susceptible to one unique mode of action. ${ }^{87}$ Further advances in BXD research would benefit from taking into account the complexity of such relationships.

Besides the target organism, evaluation of BXD activities must also account for their stability under the bioassay conditions and the possible interference of degradation products in the results. For example, it is possible for unstable BXDs to react with components of artificial diets during insect feeding bioassays producing misleading results. Similarly, ecological experiments should critically interpret bioassay results by comparison with natural conditions. The BXD defense system in plants is highly compartmentalized and relies on temporally and spatially resolved activation by hydrolysis. It is challenging to reproduce the tissue specific distribution of BXDs that herbivores and pathogens would encounter in a plant leaf, or a gradient of BXDs and their metabolites in soil as perceived by other plants, soil microorganisms, nematodes, and root herbivores. Conclusions drawn from laboratory bioassays about the ecological role of BXDs should carefully consider such aspects.

While we have tried to summarize the general reactivities described for BXDs in the literature, the subject is still not completely clear. As the benzoxazinone degradation to benzoxazolinones is not quantitative,,${ }^{53}$ it is possible that side reactions from intermediates shown in Scheme 3 or others are involved in biologically relevant activities. As with the reactive imidoquinone intermediate, ${ }^{46}$ other unknown reactive species could be generated according to medium conditions and BXD structural features. Moreover, the enzymatic activation of BXDs upon metabolism yielding reactive species, as the proposed formation of 4- $\mathrm{N}-\mathrm{O}$-acetyl derivatives, ${ }^{41}$ still needs rigorous investigation.

Studies evaluating the influence of BXD structural features on biological activity are especially important to clarify the mechanisms underlying their biological effects. Thanks to the development of several synthetic routes for BXDs and their non-natural analogs, it is relatively easy to access various structures and continue the work of elucidating BXD modes of action. Future experiments on exploring modes of action for BXDs would benefit from actively searching and chemically characterizing intermediates and end-products that could help differentiate between mechanisms. Advances in analytical chemistry and the wealth of literature concerning BXD analyses should make this process relatively straightforward for the modes of action discussed in this review. Experimental designs that include comparisons between structural analogs with different chemical features also have the potential to more clearly assign specific modes of action to the various biological activities.

To answer the remaining questions regarding the mode of action of BXDs will require integrated research involving ecology, evolution, biochemistry, analytical chemistry, organic synthesis, and other areas. The results will be valuable from many perspectives, from increasing our basic understanding of the interactions between plants and other organisms, to the development of BXD-inspired pesticides and new plant breeding strategies to increase protection by naturally-occurring BXDs.

\section{Acknowledgments}

The authors gratefully acknowledge the Swiss National Science Foundation (Grant No. 136184) and the Max Planck Society for financial support.

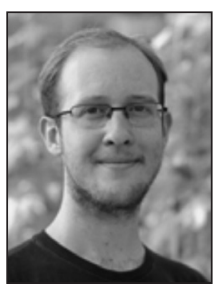

Felipe Christoff Wouters is a Bachelor in Chemistry (2010) from the Federal University of Santa Maria and obtained his Master degree in Organic Chemistry from the University of Campinas (2011) under the guidance of Prof Anita J. Marsaioli. Currently, he is a PhD student at the Max Planck Institute for Chemical Ecology (Jena, Germany) under the supervision of Prof Jonathan Gershenzon. His research is focused on the metabolism of benzoxazinoids by lepidopteran herbivores, elucidation of detoxification products, and identification of enzymes responsible for insect resistance to these plant defenses.

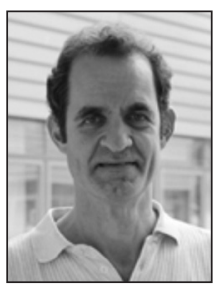

Jonathan Gershenzon received his PhD in 1984 at the University of Texas at Austin working under the supervision of Tom J. Mabry. After post-doctoral research at the Institute of Biological Chemistry, Washington State University with Rodney Croteau, he joined the Max Planck Institute of Chemical Ecology in Jena, Germany, where he is now Director of the Department 
of Biochemistry. His scientific interests include the biosynthesis of plant secondary metabolites and their roles in defense against herbivores and pathogens, emphasizing compounds such as glucosinolates, benzoxazinoids and terpenoids.

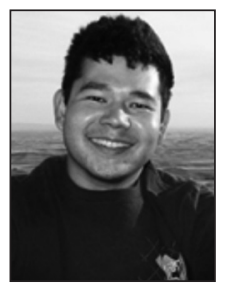

Daniel Giddings Vassão is a Bachelor in Chemistry (2001) from the University of São Paulo, where he started learning phytochemistry from Prof Massuo J. Kato, and obtained his PhD in Biochemistry from Washington State University (2008) under the guidance of Prof Norman G. Lewis. He then joined Prof Jonathan Gershenzon's Department of Biochemistry at the Max Planck Institute for Chemical Ecology, where he currently leads a research group focused on the chemistry of plant-herbivore interactions. His major research interests are in determining how insects biochemically process/detoxify phytochemicals, and in understanding the mechanisms mediating the toxicity of plant chemical defenses.

\section{References}

1. Niemeyer, H. M.; J. Agric. Food Chem. 2009, 57, 1677.

2. Frey, M.; Schullehner, K.; Dick, R.; Fiesselmann, A.; Gierl, A.; Phytochemistry 2009, 70, 1645.

3. Makowska, B.; Bakera, B.; Rakoczy-Trojanowska, M.; Acta Physiol. Plant. 2015, 37, 176.

4. Meihls, L. N.; Handrick, V.; Glauser, G.; Barbier, H.; Kaur, H.; Haribal, M. M.; Lipka, A. E.; Gershenzon, J.; Buckler, E. S.; Erb, M.; Köllner, T. G.; Jander, G.; Plant Cell 2013, 25, 2341.

5. Gierl, A.; Frey, M.; Planta 2001, 213, 493.

6. Korte, A. R.; Yandeau-Nelson, M. D.; Nikolau, B. J.; Lee, Y. J.; Anal. Bioanal. Chem. 2015, 407, 2301.

7. Nikus, J.; Daniel, G.; Jonsson, L. M.; Physiol. Plant. 2001, 111, 466.

8. Pentzold, S.; Zagrobelny, M.; Rook, F.; Bak, S.; Biol. Rev. 2014, 89, 531.

9. Morant, A. V.; Jørgensen, K.; Jørgensen, C.; Paquette, S. M.; Sanchez-Pérez, R.; Møller, B. L.; Bak, S.; Phytochemistry 2008, 69, 1795

10. Pérez, F. J.; Ormeñonuñez, J.; J. Chem. Ecol. 1991, 17, 1037.

11. Belz, R. G.; Hurle, K.; J. Agric. Food Chem. 2005, 53, 250.

12. Glauser, G.; Marti, G.; Villard, N.; Doyen, G. A.; Wolfender, J. L.; Turlings, T. C.; Erb, M.; Plant J. 2011, 68, 901.

13. Dafoe, N. J.; Huffaker, A.; Vaughan, M. M.; Duehl, A. J.; Teal, P. E.; Schmelz, E. A.; J. Chem. Ecol. 2011, 37, 984.

14. Oikawa, A.; Ishihara, A.; Iwamura, H.; Phytochemistry 2002, 61,331 .
15. Cambier, V.; Hance, T.; de Hoffmann, E.; Phytochemistry 2000, 53, 223.

16. Robert, C. A.; Veyrat, N.; Glauser, G.; Marti, G.; Doyen, G. R.; Villard, N.; Gaillard, M. D.; Köllner, T. G.; Giron, D.; Body, M.; Babst, B. A.; Ferrieri, R. A.; Turlings, T. C.; Erb, M.; Ecol. Lett. 2012, 15, 55.

17. Köhler, A.; Maag, D.; Veyrat, N.; Glauser, G.; Wolfender, J. L.; Turlings, T. C.; Erb, M.; Plant Cell Environ. 2015, 38, 1081.

18. Oikawa, A.; Ishihara, A.; Tanaka, C.; Mori, N.; Tsuda, M.; Iwamura, H.; Phytochemistry 2004, 65, 2995.

19. Oikawa, A.; Ishihara, A.; Hasegawa, M.; Kodama, O.; Iwamura, H.; Phytochemistry 2001, 56, 669.

20. Macías, F. A.; Marín, D.; Oliveros-Bastidas, A.; Molinillo, J. M. G.; Nat. Prod. Rep. 2009, 26, 478.

21. Sicker, D.; Schulz, M. In Studies in Natural Products Chemistry, vol. 27; Atta-Ur-Rahman, ed.; Elsevier: Amsterdam, Netherlands, 2002, p. 185.

22. Macías, F. A.; Marin, D.; Oliveros-Bastidas, A.; Chinchilla, D.; Simonet, A. M.; Molinillo, J. M.; J. Agric. Food Chem. 2006, $54,991$.

23. Hashimoto, Y.; Shudo, K.; Phytochemistry 1996, 43, 551.

24. Sicker, D.; Frey, M.; Schulz, M.; Gierl, A.; Int. Rev. Cytol. 2000, 198, 319.

25. Hietala, P. K.; Virtanen, A. I.; Norén, B.; Levitin, N. E.; Westin, G.; Acta Chem. Scandinav. 1960, 14, 502.

26. Copaja, S. V.; Bravo, H. R.; Niemeyer, H. M.; J. Org. Chem. 1986, $51,3542$.

27. Atkinson, J.; Morand, P.; Arnason, J. T.; Niemeyer, H. M.; Bravo, H. R.; J. Org. Chem. 1991, 56, 1788.

28. Lippmann, T.; Hartenstein, H.; Sicker, D.; Chromatographia 1993, 35, 302.

29. Thunecke, F.; Hartenstein, H.; Sicker, D.; Vogt, C.; Chromatographia 1994, 38, 470.

30. Klein, J.; Hartenstein, H.; Sicker, D.; Magn. Reson. Chem. 1994, 32,727 .

31. Kluge, M.; Grambow, H. J.; Sicker, D.; Phytochemistry 1997, 44, 639 .

32. Nagao, T.; Otsuka, H.; Kohda, H.; Sato, T.; Yamasaki, K.; Phytochemistry 1985, 24, 2959.

33. Hartenstein, H.; Klein, J.; Sicker, D.; Indian J. Heterocycl. Chem. 1993, 2, 151.

34. Hartenstein, H.; Sicker, D.; Phytochemistry 1994, 35, 827.

35. Cambier, V.; Hance, T.; de Hoffmann, E.; Phytochem. Anal. 1999, 10, 119.

36. Villagrasa, M.; Eljarrat, E.; Barceló, D.; Trends Anal. Chem. 2009, 28, 1103.

37. Bonnington, L. S.; Barceló, D.; Knepper, T. P.; J. Mass Spectrom. 2003, 38, 1054.

38. Larsen, E.; Christensen, L. P.; J. Agric. Food Chem. 2000, 48, 2556. 
39. Chandra, A.; Singh, S. B.; Kumar, P.; Environ. Monit. Assess. 2013, 185, 9917.

40. Sicker, D.; Hartenstein, H.; Hazard, R.; Tallec, A.; J. Heterocycl. Chem. 1994, 31, 809.

41. Hashimoto, Y.; Ishizaki, T.; Shudo, K.; Tetrahedron 1991, 47, 1837.

42. Kluge, M.; Sicker, D.; Tetrahedron 1996, 52, 10389.

43. Kluge, M.; Schneider, B.; Sicker, D.; Carbohyd. Res. 1997, $298,147$.

44. Virtanen, A. I.; Hietala, P. K.; Lundén, R.; Prydz, H.; Acta Chem. Scandinav. 1955, 9, 1543.

45. Virtanen, A. I.; Hietala, P. K.; Norén, B.; Levitin, N. E.; Westin, G.; Acta Chem. Scandinav. 1960, 14, 499.

46. Maresh, J.; Zhang, J.; Lynn, D. G.; ACS Chem. Biol. 2006, 1, 165.

47. Bredenberg, J. B.; Honkanen, E.; Virtanen, A. I.; Motzfeldt, K.; Theander, O.; Flood, H.; Acta Chem. Scandinav. 1962, 16, 135 .

48. Honkanen, E.; Virtanen, A. I.; Sparrman, B.; Nielsen, G. B.; Nord, H.; Jart, A.; Acta Chem. Scandinav. 1961, 15, 221.

49. Niemeyer, H. M.; Bravo, H. R.; Peña, G. F.; Corcuera, L. J. In Chemistry and Biology of Hydroxamic Acids; Kehl, H., ed.; Karger, A. G.: Basel, Switzerland, 1982, p. 22.

50. Bravo, H. R.; Niemeyer, H. M.; Tetrahedron 1985, 41, 4983.

51. Grambow, H. J.; Luckge, J.; Klausener, A.; Müller, E.; Z. Naturforsch. C 1986, 41, 684.

52. Smissman, E. E.; Corbett, M. D.; Jenny, N. A.; Kristiansen, O.: J. Org. Chem. 1972, 37, 1700.

53. Woodward, M. D.; Corcuera, L. J.; Helgeson, J. P.; Upper, C. D.; Plant Physiol. 1978, 61, 796.

54. Pérez, F. J.; Niemeyer, H. M.; Phytochemistry 1989, 28, 1831.

55. Niemeyer, H. M.; Corcuera, L. J.; Pérez, F. J.; Phytochemistry 1982, 21, 2287.

56. Ishizaki, T.; Hashimoto, Y.; Shudo, K.; Okamoto, T.; Tetrahedron Lett. 1982, 23, 4055.

57. Hashimoto, Y.; Shudo, K.; Okamoto, T.; Nagao, M.; Takahashi, Y.; Sugimura, T.; Mutat. Res. 1979, 66, 191.

58. Quiroz, A.; Niemeyer, H. M.; Heterocycles 1991, 32, 1681.

59. Dixon, D. P.; Sellars, J. D.; Kenwright, A. M.; Steel, P. G.; Phytochemistry 2012, 77, 171.

60. Padró, J. M.; Acquaviva, A.; Tascon, M.; Gagliardi, L. G.; Castells, C. B.; Anal. Chim. Acta 2012, 725, 87.

61. Shudo, K.; Orihara, Y.; Ohta, T.; Okamoto, T.; J. Am. Chem. Soc. 1981, 103, 943.

62. Miller, M. J.; Chem. Rev. 1989, 89, 1563.

63. Hider, R. C.; Kong, X.; Nat. Prod. Rep. 2010, 27, 637.

64. Braun, V.; Pramanik, A.; Gwinner, T.; Koberle, M.; Bohn, E.; Biometals 2009, 22, 3.

65. Tipton, C. L.; Buell, E. L.; Phytochemistry 1970, 9, 1215.

66. Dabed, R. G.; Toral, M. I.; Corcuera, L. J.; Niemeyer, H. M.; Polyhedron 1983, 2, 106.
67. Hiriart, M. V.; Corcuera, L. J.; Andrade, C.; Crivelli, I.; Phytochemistry 1985, 24, 1919.

68. Bigler, L.; Baumeler, A.; Werner, C.; Hesse, M.; Helv. Chim. Acta 1996, 79, 1701.

69. Farkas, E.; Kozma, E.; Pethő, M.; Herlihy, K. M.; Micera, C.; Polyhedron 1998, 17, 3331.

70. Pethö, M.; Acta Agron. Hung. 1992, 41, 57.

71. Pethő, M.; Acta Agron. Hung. 1992, 41, 167.

72. Pethő, M.; Acta Agron. Hung. 1993, 42, 203.

73. Pethö, M.; Acta Biol. (Szeged) 2002, 46, 175.

74. Poschenrieder, C.; Tolra, R. P.; Barceló, J.; J. Inorg. Biochem. 2005, 99, 1830.

75. Venturelli, S.; Belz, R. G.; Kämper, A.; Berger, A.; von Horn, K.; Wegner, A.; Böcker, A.; Zabulon, G.; Langenecker, T.; Kohlbacher, O.; Barneche, F.; Weigel, D.; Lauer, U. M.; Bitzer, M.; Becker, C.; Plant Cell 2015, 27, 3175.

76. Adhikari, K. B.; Tanwir, F.; Gregersen, P. L.; Steffensen, S. K.; Jensen, B. M.; Poulsen, L. K.; Nielsen, C. H.; Høyer, S.; Borre, M.; Fomsgaard, I. S.; Mol. Nutr. Food Res. 2015, 59, 1324.

77. Venis, M. A.; Watson, P. J.; Planta 1978, 142, 103.

78. Hasegawa, K.; Togo, S.; Urashima, M.; Mizutani, J.; Kosemura, S.; Yamamura, S.; Phytochemistry 1992, 31, 3673.

79. Hoshisakoda, M.; Usui, K.; Ishizuka, K.; Kosemura, S.; Yamamura, S.; Hasegawa, K.; Phytochemistry 1994, 37, 297.

80. Fomsgaard, I. S.; Mortensen, A. G.; Carlsen, S. C.; Chemosphere 2004, 54, 1025.

81. Schulz, M.; Marocco, A.; Tabaglio, V.; Macías, F. A.; Molinillo, J. M.; J. Chem. Ecol. 2013, 39, 154.

82. Kato-Noguchi, H.; Macías, F. A.; Molinillo, J. M.; J. Plant Physiol. 2010, 167, 1221.

83. Li, X. J.; Xia, Z. C.; Kong, C. H.; Xu, X. H.; J. Agric. Food Chem. 2013, 61, 5072.

84. Rice, C. P.; Cai, G.; Teasdale, J. R.; J. Agric. Food Chem. 2012, $60,4471$.

85. Pérez, F. J.; Niemeyer, H. M.; Phytochemistry 1989, 28, 1597.

86. Cuevas, L.; Niemeyer, H. M.; Pérez, F. J.; Phytochemistry 1990, 29, 1429.

87. Duffey, S. S.; Stout, M. J.; Arch. Insect Biochem. 1996, 32, 3.

88. Atkinson, J.; Arnason, J.; Campos, F.; Niemeyer, H. M.; Bravo, H. R. In Synthesis and Chemistry of Agrochemicals III; Baker, D. R.; Fenyes, J. G.; Steffens, J. J., eds.; ACS Symposium Series 504, American Chemical Society: Washington, DC, 1992, p. 349.

89. Wouters, F. C.; Reichelt, M.; Glauser, G.; Bauer, E.; Erb, M.; Gershenzon, J.; Vassão, D. G.; Angew. Chemie Int. Ed. 2014, 53, 11320.

90. Escobar, C. A.; Sicker, D.; Niemeyer, H. M.; J. Chem. Ecol. 1999, 25, 1543.

91. Bravo, H. R.; Copaja, S. V.; Argandoña, V. H.; J. Agric. Food Chem. 2004, 52, 2598.

92. Cambier, V.; Hance, T.; de Hoffmann, E.; J. Chem. Ecol. 2001, 27,359 . 
93. Bravo, H. R.; Lazo, W.; Phytochemistry 1993, 33, 569.

94. Bravo, H. R.; Lazo, W.; J. Agric. Food Chem. 1996, 44, 1569.

95. Bravo, H. R.; Copaja, S. V.; Lazo, W.; J. Agric. Food Chem. 1997, 45, 3255.

96. Macías, F. A.; Marín, D.; Oliveros-Bastidas, A.; Castellano, D.; Simonet, A. M.; Molinillo, J. M.; J. Agric. Food Chem. 2005, 53, 538 .

97. Macías, F. A.; Marín, D.; Oliveros-Bastidas, A.; Castellano, D.; Simonet, A. M.; Molinillo, J. M.; J. Agric. Food Chem. 2006, 54,1040 .
98. Macías, F. A.; Marín, D.; Oliveros-Bastidas, A.; Molinillo, J. M.; J. Agric. Food Chem. 2006, 54, 9357.

99. Macías, F. A.; de Siqueira, J. M.; Chinchilla, N.; Marín, D.; Varela, R. M.; Molinillo, J. M.; J. Agric. Food Chem. 2006, 54 , 9843.

100. Macías, F. A.; Chinchilla, N.; Arroyo, E.; Molinillo, J. M.; Marín, D.; Varela, R. M.; J. Agric. Food Chem. 2010, 58, 2047.

Submitted: March 7, 2016

Published online: June 9, 2016 